\title{
Association of the polymorphism in GYS1 and ACOX1 genes with meat quality traits in pigs
}

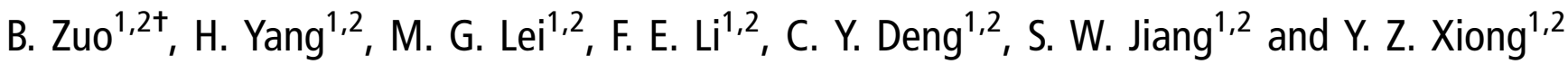 \\ ${ }^{1}$ Key Laboratory of Swine Genetics and Breeding, Ministry of Agriculture, College of Animal Science and Veterinary Medicine, Huazhong Agricultural University, \\ Wuhan 430070, People's Republic of China; ${ }^{2}$ Key Laboratory of Agricultural Animal Genetics, Breeding and Reproduction, Ministry of Education, College of \\ Animal Science and Veterinary Medicine, Huazhong Agricultural University, Wuhan 430070, People's Republic of China
}

(Received 21 January 2007; Accepted 25 June 2007)

\begin{abstract}
Phenotypic information about several pig meat quality traits on 334 Large White $\times$ Meishan $F_{2}$ pigs was collected. Effects of the association of the Fokl variants in the seventh intron of the skeletal muscle glycogen synthase (GYS1) gene and the Pst/ variants in the ninth intron of the palmitoyl acyl-COA oxidase 1 (ACOX1) gene on the meat quality traits were examined on all pigs. The FokI variants of the GYS1 gene showed significant effects on $\mathrm{pH}$ of $\mathrm{m}$. semipinalis capitis $(\mathrm{P}<0.05)$. Linkage analysis indicated that the peak of the quantitative trait loci (QTL) curve was located around this marker for $p H$, but it did not reach significance $(\mathrm{P}>0.05)$. The results may be due to several reasons such as linkage disequilibrium to the causal mutations, the limited number of animals or balance of another QTL or marker with negative effects. Significant effects of Pst/ variants of ACOX1 gene were also found on meat colour value and meat marbling score of both $\mathrm{m}$. longissimus dorsi and $\mathrm{m}$. biceps femoris $(P<0.05)$. Dominant effects for the affected traits at those two loci were significant except for meat marbling score of $\mathrm{m}$. biceps femoris $(\mathrm{P}<0.05)$. The results of this study give us some evidence for the potential of those dominant markers used in the marker-assisted selection of crossbreeding of the Large White pig sire lines and Meishan-derived synthetic dam lines.
\end{abstract}

Keywords: ACOX1, GYS1, marker-assisted selection, meat quality, pigs

\section{Introduction}

For the last years, meat quality traits have increasingly attracted more attention in pig breeding because selection for high growth rate and lean meat deposition resulted in reduction of meat quality such as the increasing incidence of PSE (pale, soft and exudative) muscle and decreasing of intramuscular fat (IMF) content (Zuo et al., 2003). Use of marker-assisted selection (MAS) is especially interesting for meat quality traits, because improvement of meat quality is difficult using conventional selection methods since most traits of interest can only be measured after slaughter and, therefore, only information on relatives can be used for selection (Malek et al., 2001). The successful application of MAS in the animal population will depend on the identification of major genes or tightly linked markers. The study of associations of candidate genes is a step for the knowledge of the genetic basis of productive traits, and compared with other genomic approaches (quantitative trait loci (QTL)

\footnotetext{
† E-mail: zuobo@mail.hzau.edu.cn
}

detection) is potentially more easily and efficiently implemented in breeding programmes (Ovilo et al., 2006).

The skeletal muscle glycogen synthase (GYS1) gene is a key enzyme of non-oxidative pathway of glucose metabolism that has been reported to be related to insulin resistance in non-insulin-dependent diabetic (NIDDM) patients (Rissanen et al., 1997; Shimomura et al., 1997; OrhoMelander et al., 1999; Fenger et al., 2000; Motoyama et al., 2003). The A/G mutation in intron 14 of the porcine GYS1 gene has been discovered, but has no effect on the content of glycogen in skeletal muscle (Te Pas et al., 2003). Preoxisomal acyl-CoA oxidase 1 (ACOX1) catalyses the betaoxidation of very long-chain fatty acids, and thus plays an essential role in fatty acid degradation. Fan et al. (1996) found that homozygous ACOX1-null mice were viable, but growth retarded and infertile. Expression of the ACOX1 gene was significantly increased in male mice fed a high-fat diet, compared with a low-fat diet (Kim et al., 2004). The porcine GYS1 and ACOX1 gene was physically mapped to SSC6 and SSC12, respectively (Cirera et al., 2003; Fontanesi et al., 2003), where significant QTL affecting meat quality traits have been reported (De Koning et al., 1999; Clop 
et al., 2003). Therefore, those two genes have been suggested as the promising candidate genes for meat quality traits, given their roles in the glycogen synthesis and metabolism of fatty acids.

Compared with the Chinese fat-type Meishan pigs, the meat-type Large White pigs have a higher growth rate, higher feed to body weight conversion ratio and higher carcass lean percentage, but have lower IMF and inferior eating quality from the Chinese perspective. In order to seek for the major gene or marker underlying the important economic traits such as meat quality traits, a three generation resource family was established by Large White boars and Meishan dams in our lab. The objective of the current study was to detect Fokl restriction endonuclease variants in the seventh intron of the GYS1 gene and Pstl restriction endonuclease variants in the ninth intron of the ACOX1 gene in the Large White $\times$ Meishan pig resource family, and to determine whether these were associated with variation in meat quality traits, and thus could contribute to breeding programmes.

\section{Material and methods}

\section{Animals and data collection}

Two $F_{2}$ populations used in the association analysis were derived from the intercross of Large White and Meishan pigs. One population was formed by $140 F_{2}, 28 F_{1}$ and 10 grandparent animals in 16 full-sib families, and the other population consisted of $194 F_{2}, 26 F_{1}$ and 11 grandparent animals in 21 full-sib families. They were fed twice daily with diets formulated according to age under a standardised feeding regimen and free access to water. The average live weight at slaughter was $87.0 \pm 7.07 \mathrm{~kg}$. The $F_{2}$ pigs were slaughtered at 2000 and 2003 following a common protocol (Xiong and Deng, 1999). Meat quality traits including $\mathrm{pH}$ of $m$. longissimus dorsi at post slaughter $45 \mathrm{~min}$ (pHLD), pH of $m$. biceps femoris at post slaughter $45 \mathrm{~min}$ (pHBF), pH of $\mathrm{m}$. semipinalis capitis at post slaughter $45 \mathrm{~min}$ (pHSC), drip loss rate (DLR, \%), waterholding capacity (WHC, \%), meat colour value of $m$. longissimus dorsi (MCV1), meat colour value of $m$. biceps femoris (MCV2), meat marbling score of $m$. longissimus dorsi (MMS1), meat marbling score of $m$. biceps femoris (MMS2), IMF (\%) and water moisture (WM, \%) were measured according to the method of Xiong and Deng (1999). Genomic DNA was prepared from blood samples using a standard phenol: chloroform extraction method.

\section{PCR-RFLP genotyping}

The DNA from the $F_{2}$ pigs was used as template to perform PCR. According to the obtained CDNA sequences (Genbank accession number AY870324) and the exon/intron organisation of human GYS1 gene, PCR primers (forward: 5' - TAT GAG TTC TCC AAC AAG GGG -3'; reverse: 5'- GAT GAA GAA AGC AAC CAC TGT C $-3^{\prime}$ ) were designed to amplify porcine GYS1 gene. According to the obtained CDNA sequences (Genbank accession number DQ842227) and the exon/intron organisation of human $A C O X 1$ gene, $P C R$ primers (forward: 5'- GGA AAT GAA CCC GAC CAG TA -3'; reverse: $5^{\prime}$ - TGC GTC TCA GGA AGC AGT AAG -3') were designed to amplify porcine $A C O X 1$ gene. The reaction mixtures comprised $25 \mathrm{ng}$ porcine genomic DNA as template, $0.25 \mu \mathrm{mol} / \mathrm{l}$ of each primer, $0.25 \mu \mathrm{mol} / / \mathrm{l}$ of each $\mathrm{dNTP}$, $1 \times$ PCR buffer and $1 \mathrm{U}$ Taq DNA polymerase (Biostar Internation, Toronto, Canada). The PCR amplifications were performed in $20 \mu \mathrm{l}$ on a GeneAmp PCR system 9600 (Perkin Elmer, Foster City, CA, USA) with the following cycling parameters: $95^{\circ} \mathrm{C}$ initial denaturation for 4 min, 35 cycles of $95^{\circ} \mathrm{C}$ denaturation for $45 \mathrm{~s}, 60^{\circ} \mathrm{C}(\mathrm{GYS} 1)$ or $61^{\circ} \mathrm{C}$ (ACOX1) annealing for $45 \mathrm{~s}$, and $72^{\circ} \mathrm{C}$ extension for $45 \mathrm{~s}$. A final extension was performed at $72^{\circ} \mathrm{C}$ for $10 \mathrm{~min} .8 \mu \mathrm{l}$ of PCR amplifications obtained with above primer pairs were digested with $10 \mathrm{U}$ Fokl and Pstl restriction enzyme (TaKaRa, Dalian, China), electrophoresed on 1.5\% (GYS1) or $2.5 \%$ (ACOX1) agarose gel in $1 \times$ TAE buffer and stained with $0.5 \mu \mathrm{g} / \mathrm{ml}$ ethidium bromide.

\section{Analysis}

The effects of single genotypes on the traits studied were analysed by the least-squares method as applied in the general linear model (GLM) procedure of Statistical Analysis Systems Institute (SAS; 2000) according to the following statistical model:

$$
T_{i j k l}=\mu+S_{i}+Y_{j}+G_{k}+F_{l}+b_{i j k l} X_{i j k l}+e_{i j k l},
$$

where $T_{i j k l}$ is the observed values of a given trait, $\mu$ is the overall mean, $S_{i}$ is effect of sex ( $i=1$ for male or 2 for female), $Y_{j}$ is the effect of year $(j=1$ for year 2000 or 2 for year 2003), $G_{k}$ is the effect of genotype ( $k=A A, A B$ and $B B), F_{l}$ is the effect of family $(I=37), b_{i j k l}$ is the regression coefficient of the slaughter age for meat quality traits, $X_{i j k l}$ is the slaughter age, and $e_{i j k l}$ is the random residual. Both additive and dominance effects were estimated using the REG procedure of SAS version 8.0, where the contrast coefficients for the additive effect were denoted as $-1,0$ and 1 for $A A, A B$ and $B B$, respectively, and the contrast coefficients for the dominance effect were denoted as 1 , -1 and 1 for $A A, A B$ and $B B$, respectively (Liu, 1998).

In order to determine whether the significant associations of GYS1 gene were due to the marker or due to other co-inherited blocks, the genetic mapping were performed by CRI-MAP software version 2.4 (Green et al., 1990) using genotypes for Fokl PCR-RFLP and four microsatellite markers (SW1302, SW1473, S0121 and SW322) information available on SSC6 (Zuo et al., 2005; Zhang et al., 2007). Least-square regression interval mapping as described by Haley et al. (1994) was used for QTL detection. QTL analysis was carried out on the Internet (http://qtl.cap.ed.ac.uk). For the meat quality traits, sex, year and full-sib family were included as fixed effects with the slaughter date as a covariate. 
Table 1 Phenotypic means, standard deviation (s.d.) and coefficients of variation (CV) for meat quality traits

\begin{tabular}{lllrrr}
\hline \hline Trait & Symbol & No. & Mean & s.d. & CV (\%) \\
\hline pH (m. longissimus dorsi) & pHLD & 334 & 6.34 & 0.18 & 2.89 \\
pH (m. biceps femoris) & pHBF & 334 & 6.40 & 0.13 & 2.03 \\
pH (m. semipinalis capitis) & pHSC & 334 & 6.44 & 0.12 & 1.86 \\
$\begin{array}{l}\text { Drip loss rate } \\
\text { Water-holding capacity }\end{array}$ & DLR & 327 & 6.25 & 1.44 & 23.02 \\
$\begin{array}{l}\text { Meat colour value } \\
\text { (m. longissimus dorsi) }\end{array}$ & MCV1 & 327 & 91.50 & 2.05 & 2.24 \\
$\begin{array}{l}\text { Meat colour value } \\
\text { (m. biceps femoris) }\end{array}$ & MCV2 & 334 & 19.05 & 1.70 & 8.92 \\
$\begin{array}{l}\text { Meat marbling score } \\
\text { (m. longissimus dorsi) }\end{array}$ & MMS1 & 334 & 3.43 & 0.24 & 7.00 \\
$\begin{array}{l}\text { Meat marbling score } \\
\text { (m. biceps femoris) }\end{array}$ & MMS2 & 334 & 4.10 & 0.18 & 4.39 \\
$\begin{array}{l}\text { Intramuscular fat } \\
\text { (m. longissimus dorsi) }\end{array}$ & IMF & 334 & 3.19 & 0.86 & 27.00 \\
$\begin{array}{l}\text { Water moisture } \\
\text { (m. longissimus dorsi) }\end{array}$ & WM & 334 & 73.78 & 0.77 & 1.04 \\
\hline \hline
\end{tabular}

Table 2 Distribution of genotypic and allelic frequencies in the resource population

\begin{tabular}{|c|c|c|c|c|c|c|c|c|}
\hline \multirow[b]{2}{*}{ Gene } & \multirow{2}{*}{$\begin{array}{l}\text { Populaton } \\
\text { (year) }\end{array}$} & \multirow[b]{2}{*}{ Generation } & \multirow[b]{2}{*}{ No. } & \multicolumn{3}{|c|}{ Genotype } & \multicolumn{2}{|c|}{ Allele frequency } \\
\hline & & & & $A A$ & $A B$ & $B B$ & $A$ & $B$ \\
\hline \multirow[t]{6}{*}{ GYS1 } & Popula & $\mathrm{F}_{0}$ & 10 & 3 & 2 & 5 & 0.40 & 0.60 \\
\hline & $(2000$ & $\mathrm{F}_{1}$ & 28 & 2 & 26 & 0 & 0.54 & 0.46 \\
\hline & & $\mathrm{F}_{2}$ & 138 & 35 & 72 & 31 & 0.51 & 0.49 \\
\hline & Population & $\mathrm{F}_{0}$ & 11 & 3 & 4 & 4 & 0.45 & 0.55 \\
\hline & (2003) & $\mathrm{F}_{1}$ & 26 & 9 & 17 & 0 & 0.67 & 0.33 \\
\hline & & $\mathrm{F}_{2}$ & 172 & 67 & 84 & 21 & 0.63 & 0.37 \\
\hline \multirow[t]{6}{*}{ ACOX1 } & Population & $\mathrm{F}_{0}$ & 10 & 3 & 0 & 7 & 0.30 & 0.70 \\
\hline & $(2000)$ & $\mathrm{F}_{1}$ & 28 & 0 & 28 & 0 & 0.50 & 0.50 \\
\hline & & $\mathrm{F}_{2}$ & 139 & 35 & 71 & 33 & 0.51 & 0.49 \\
\hline & Population & $\mathrm{F}_{0}$ & 11 & 3 & 0 & 8 & 0.27 & 0.73 \\
\hline & (2003) & $\mathrm{F}_{1}$ & 26 & 0 & 26 & 0 & 0.50 & 0.50 \\
\hline & & $\mathrm{F}_{2}$ & 159 & 37 & 88 & 34 & 0.51 & 0.49 \\
\hline
\end{tabular}

\section{Results}

Phenotype, genotype and allele frequencies

Phenotypic means, standard deviations (s.d.) and coefficients of variation (CV) for meat quality traits were given in Table 1. From this table, it was found that the CVs ranged from 1.04 to $31.80 \%$. The traits such as DLR, meat colour value, IMF content had the higher CV, while the other traits showed relatively lower variation. The distribution of genotypic and allelic frequencies in the pig population is given in Table 2. Overall, the allele frequencies showed almost equal proportion of alleles for these two genes except the GYS1 allele frequency in population 2003. For the analysis of the
Table 3 Expected frequencies of combined genotypes and comparison of observed and expected numbers of animals

\begin{tabular}{lccc}
\hline \hline & & \multicolumn{2}{c}{ No. of animals } \\
\cline { 3 - 4 } Combined genotypes & Expected frequency & Observed & Expected \\
\hline AAAA (1) & 0.0792 & 28 & 23.2 \\
AAAB (2) & 0.1782 & 49 & 52.2 \\
AABB (3) & 0.0726 & 22 & 21.2 \\
ABAA (4) & 0.1200 & 30 & 35.2 \\
ABAB (5) & 0.2700 & 83 & 79.1 \\
ABBB (6) & 0.1100 & 32 & 32.2 \\
BBAA (7) & 0.0408 & 14 & 12.0 \\
BBAB (8) & 0.0918 & 24 & 26.9 \\
BBBB (9) & 0.0374 & 11 & 11.0 \\
\hline \hline
\end{tabular}

combined genotypes, the expected frequencies of the genotypes and their combinations were calculated by simple allele counting. All of the $9\left(3^{2}\right)$ theoretically possible combinations of two individual genotypes were observed and most of the combined genotypes found clearly followed the Hardy-Weinberg equilibrium (Table 3), showing that both genes, GYS1 and ACOX1, are independent which seems reasonable as they are located in different chromosomes, GYS1 in chromosome 6 and ACOX1 in chromosome 12.

\section{GYS1 gene effects}

The results of the GLM analysis of association between the GYS1 gene and meat quality performance in pigs are summarised in Table 4. Differences among Fokl genotypes were only significant for $\mathrm{pH}$ of $m$. semipinalis capitis. No differences were detected for other meat quality traits. The $A B$ pigs had significantly higher $\mathrm{pH}$ of $m$. semipinalis capitis than $A A$ pigs, but there was no significant difference as compared with $B B$. This locus seemed to be significantly dominant in action and the dominance effects were $-0.012 \pm 0.007$ for $\mathrm{pH}$ of $m$. semipinalis capitis.

Linkage analysis showed that the Fokl marker was significantly linked with the selected markers on SSC6. Two-point linkage analysis revealed linkage to microsatellite markers SW1302 (recombination fraction $=0.25$; $L O D=7.02$ ) and SW1473 (recombination fraction $=0.20$; $\mathrm{LOD}=9.76$ ) on the sex-average linkage. The most probable order produced by Build option is as follows (Kosambi cM; sex-average values): SW1302-26.9 - GYS1-21.3 SW1473-23.3 - S0121-27.8 - SW322. However, the QTL analysis showed that there was no significant QTL for meat quality traits.

\section{ACOX1 gene effects}

The results of the GLM analysis of association between the ACOX1 gene and traits in pigs were summarised in Table 6 . Significant effects of $A C O X 1$ alleles were found on meat colour value of $m$. longissimus dorsi (MCV1), meat colour value of $m$. biceps femoris (MCV2), meat marbling score 
Table 4 Statistical analysis of association between GYS1 FokI-RFLP genotypes with meat quality traits

\begin{tabular}{lccrrrr}
\hline \hline & \multicolumn{3}{c}{ Fokl-RFLP genotype (mean \pm s.e.) } & & \multicolumn{2}{c}{ Genetic effects (mean \pm s.e.) } \\
\cline { 2 - 4 } \cline { 5 - 7 } Traits & Genotype $A A(n=102)$ & Genotype $A B(n=156)$ & Genotype $B B(n=52)$ & & Additive & Dominance \\
\hline PHLD & $6.328 \pm 0.018$ & $6.341 \pm 0.014$ & $6.376 \pm 0.025$ & & $0.023 \pm 0.015$ & $0.004 \pm 0.011$ \\
PHBF & $6.417 \pm 0.013$ & $6.415 \pm 0.010$ & $6.429 \pm 0.018$ & & $0.005 \pm 0.011$ & $0.003 \pm 0.008$ \\
PHSC & $6.426^{\mathrm{a}} \pm 0.012$ & $6.457 \pm 0.010^{\mathrm{b}}$ & $6.447^{\mathrm{a}, \mathrm{b}} \pm 0.017$ & & $0.009 \pm 0.010$ & $-0.012^{*} \pm 0.007$ \\
WLR, \% & $6.904 \pm 0.369$ & $6.703 \pm 0.296$ & $6.500 \pm 0.523$ & & $-0.195 \pm 0.323$ & $0.006 \pm 0.218$ \\
WHC, \% & $90.647 \pm 0.509$ & $90.825 \pm 0.409$ & $91.189 \pm 0.721$ & & $0.261 \pm 0.447$ & $0.037 \pm 0.300$ \\
MCV1 & $20.632 \pm 0.289$ & $20.271 \pm 0.232$ & $19.897 \pm 0.409$ & & $-0.351 \pm 0.254$ & $0.010 \pm 0.171$ \\
MCV2 & $19.263 \pm 0.112$ & $19.038 \pm 0.090$ & $19.181 \pm 0.158$ & & $-0.034 \pm 0.098$ & $0.096 \pm 0.066$ \\
MMS1 & $3.424 \pm 0.018$ & $3.413 \pm 0.015$ & $3.449 \pm 0.026$ & & $0.010 \pm 0.016$ & $0.010 \pm 0.011$ \\
MMS2 & $4.100 \pm 0.017$ & $4.096 \pm 0.014$ & $4.128 \pm 0.024$ & & $0.010 \pm 0.015$ & $0.010 \pm 0.010$ \\
IMF, \% & $3.105 \pm 0.054$ & $3.156 \pm 0.043$ & $3.175 \pm 0.076$ & & $0.021 \pm 0.047$ & $-0.019 \pm 0.032$ \\
WM, \% & $73.824 \pm 0.075$ & $73.771 \pm 0.060$ & $73.826 \pm 0.106$ & & $0.005 \pm 0.065$ & $0.031 \pm 0.044$ \\
\hline \hline
\end{tabular}

\footnotetext{
${ }^{a, b}$ Within a row, means marked with different superscript letters are significantly different $(P<0.05)$.
}

of $m$. longissimus dorsi (MMS1), and meat marbling score of $m$. biceps femoris (MMS2). This locus seemed to be significantly over-dominant in action for meat colour value and meat marbling score, and pigs with genotype $A B$ had significantly lower meat colour value, but higher meat marbling score as compared those with genotype $B B$. However, other important meat quality traits, such as water moisture and $\mathrm{pH}$, were scarcely affected by $A C O X 1$ alleles.

\section{Discussion}

The present work was based on the analysis of a $F_{2}$ segregation population derived from the intercross of Chinese Meishan and Large White pigs. Due to the significant phenotypic difference between Large White and Meishan pigs, the $F_{2}$ segregation population showed great variation in meat quality traits. The frequency of genotypes $A A, A B$ and $B B$ for $A C O X 1$ gene conformed to $1: 2: 1$ Mendelian segregation, because the $A$ allele was fixed in the founder Large White pigs and $B$ allele fixed in the founder Chinese Meishan pigs.

Ultimate $\mathrm{pH}$ of pork is the most commonly used trait to assess pork quality. A higher level of acidity within the muscle (lower $\mathrm{pH}$ ) causes muscle protein to denature and lose the ability to hold water. Therefore, meat with higher $\mathrm{pH}$ will tend to have more desirable characteristics (Malek et al., 2001). The pH of pork is correlated with glycogen content and glycolysis in postmortem muscle. GYS1 is a key enzyme of non-oxidative pathway of glucose metabolism and has been shown to strongly influence muscle glycogen content and glycolysis in skeletal muscle. This study demonstrates a significant genotype effect of GYS1 on pHSC, which is in good agreement with physiological functions of GYS1 gene. In order to discriminate between causal and neutral mutations in the $F_{2}$ design, we made use of the information provided by the neutral genetic markers located in the adjacent region of this mutation and conducted the QTL analysis. The peak of QTL for pH was
Table 5 Estimated effects (mean \pm s.e.) of QTL for $\mathrm{pH}$ on pig chromosome 6

\begin{tabular}{lcccr}
\hline \hline Trait & $\begin{array}{c}\text { Marker interval } \\
(\mathrm{cM})\end{array}$ & F-value & $\begin{array}{c}\text { Additive } \\
\text { effect }\end{array}$ & \multicolumn{1}{c}{$\begin{array}{c}\text { Dominant } \\
\text { effect }\end{array}$} \\
\hline pHLD & GYS1-SW1473 (33 cM) & 2.29 & $0.024 \pm 0.031$ & $0.015 \pm 0.023$ \\
pHBF & SW1302-GYS1 (22 cM) & 2.76 & $0.009 \pm 0.017$ & $0.012 \pm 0.016$ \\
pHSC & GYS1-SW1473 (29 cM) & 3.92 & $0.011 \pm 0.025$ & $-0.018 \pm 0.013$ \\
\hline \hline
\end{tabular}

located around the mutation of GYS1 gene and F-ratio of QTL for pHSC was higher than that of pHLD and pHBF (Table 5). Therefore, the size of the GYS1 genotype effects on the different muscle $\mathrm{pH}$ in the association study may mainly depend on the linked QTL effects. However, no significant QTL for pHSC was detected on this region although significant association of this mutation with pHSC was found in the single marker association. It may be due to several reasons. (1) The $F_{2}$ design has a great power to detect QTL provided by linkage disequilibrium, and also makes it difficult to discriminate between causal and neutral mutations. Therefore, a high percentage of false positives can be expected (Varona et al., 2005). (2) The number of animals we detected is not enough to demonstrate the true event. (3) The significant effects of GYS1 gene were balanced by another QTL or marker with negative effects, as the QTL region was broad. All these need further verification.

ACOX1 is the first and rate-limiting enzyme in the peroxisomal fatty acid beta-oxidation pathway, suggesting this gene may be a potential candidate gene for the traits related to fat metabolism. IMF content is a major determinant of meat quality. After the elimination of the halothane mutation, the next limiting factor for meat quality would be IMF (Webb, 1998). The IMF can be measured by subjective and objective methods. Meat marbling score is one of subjective methods. The more the IMF content, the higher the meat marbling score. This study showed a significant effect of $A C O X 1$ on meat marbling score. Although 
Table 6 Statistical analysis of association between ACOX1 Pst/-RFLP genotypes with meat quality traits

\begin{tabular}{lcccrrr}
\hline \hline & \multicolumn{3}{c}{ ACOX1-Pstl-RFLP genotype (mean \pm s.e.) } & & \multicolumn{2}{c}{ Genetic effects (mean \pm s.e.) } \\
\cline { 2 - 5 } Trait & Genotype $A A(n=72)$ & Genotype $A B(n=159)$ & Genotype $B B(n=67)$ & & Additive & Dominance \\
\hline PHLD & $6.325 \pm 0.022$ & $6.354 \pm 0.014$ & $6.342 \pm 0.022$ & & $0.008 \pm 0.015$ & $-0.010 \pm 0.011$ \\
PHBF & $6.400 \pm 0.015$ & $6.426 \pm 0.01$ & $6.423 \pm 0.016$ & & $0.012 \pm 0.011$ & $-0.008 \pm 0.008$ \\
PHSC & $6.432 \pm 0.015$ & $6.444 \pm 0.01$ & $6.462 \pm 0.015$ & & $0.016 \pm 0.010$ & $0.000 \pm 0.007$ \\
WLR, \% & $6.634 \pm 0.446$ & $6.502 \pm 0.298$ & $7.482 \pm 0.459$ & & $0.424 \pm 0.319$ & $0.278 \pm 0.219$ \\
WHC, \% & $90.839 \pm 0.616$ & $91.19 \pm 0.412$ & $89.828 \pm 0.633$ & & $-0.507 \pm 0.441$ & $-0.428 \pm 0.303$ \\
MCV1 & $20.304^{\mathrm{a}, \mathrm{b}} \pm 0.349$ & $20.115^{\mathrm{a}} \pm 0.233$ & $21.08^{\mathrm{b}} \pm 0.359$ & & $0.396 \pm 0.250$ & $0.282^{*} \pm 0.171$ \\
MCV2 & $19.163^{\mathrm{a}, \mathrm{b}} \pm 0.134$ & $19.042^{\mathrm{a}} \pm 0.089$ & $19.465^{\mathrm{b}} \pm 0.137$ & & $0.156 \pm 0.096$ & $0.132^{*} \pm 0.066$ \\
MMS1 & $3.413^{\mathrm{a}, \mathrm{b}} \pm 0.022$ & $3.449^{\mathrm{a}} \pm 0.015$ & $3.373^{\mathrm{b}} \pm 0.023$ & & $-0.022 \pm 0.016$ & $-0.027^{*} \pm 0.011$ \\
MMS2 & $4.102^{\mathrm{a}, \mathrm{b}} \pm 0.021$ & $4.129^{\mathrm{a}} \pm 0.014$ & $4.073^{\mathrm{b}} \pm 0.022$ & & $-0.015 \pm 0.015$ & $-0.020 \pm 0.010$ \\
IMF, \% & $3.069 \pm 0.066$ & $3.176 \pm 0.044$ & $3.054 \pm 0.068$ & & $-0.010 \pm 0.047$ & $-0.055 \pm 0.032$ \\
WM, \% & $73.854 \pm 0.091$ & $73.784 \pm 0.061$ & $73.755 \pm 0.094$ & & $-0.050 \pm 0.045$ & $-0.010 \pm 0.042$ \\
\hline \hline
\end{tabular}

a,b Within a row, means marked with different superscript letters are significantly different $(P<0.05)$.

this SNP did not significantly contribute to the variation in IMF content in this population, the effect of this locus still approached the $P<0.05$ statistical level (data not shown). As we have not performed the QTL analysis in this chromosome, we cannot determine whether the significant associations are due to the marker or due to other coinherited blocks. However, the dominance effects were consistent within two $F_{2}$ populations except for the effects on MMS2 (data not shown).

The potential gain of MAS would be in terms of reduced costs for sib testing after slaughter and reduction in sophisticated meat quality measurements as well as additional improvement of meat quality by early information from genetic markers (Ovilo et al., 2006). At present, most of the market pigs are the hybrids among different specialised pig sire and dam lines. As for the dominant markers in the MAS programme, one of the alleles can be selected in sire line, and the other allele selected in the dam line, so the dominant effects can be realised in the hybrids. From this point of view, we can select the allele from Meishan pigs in the synthetic dam lines, and then the dam line can be crossbred with Large White pig sire lines. However, before the selection of these markers in the specialised dam lines, we should confirm the effects of those markers by comparing the meat quality traits of crossbred pigs carrying different genotypes, as the alternative allele was not completely fixed in the synthetic dam lines prior to the selection. In addition, we have to re-test for the effects in different crossbred populations, because it is likely that this polymorphism indirectly affects meat quality traits by being in linkage disequilibrium with another polymorphism that directly influences the quantitative traits analysed.

\section{Conclusions}

The results showed that the Fokl variants of the GYS1 gene was significantly associated with pHSC in the association studies, but when taken into account the information provided by the neutral genetic markers on this chromosome, the peak of the QTL curve was located around this marker for $\mathrm{pH}$, but it did not reach significance level. The effects of the Pstl variants in the ninth intron of the ACOX1 gene polymorphism on marbling and IMF were consistent. These two loci seemed to be significantly dominant in action. Those dominant markers could be used in the MAS of crossbreeding of specialised pig sire and dam lines.

\section{Acknowledgements}

This study was supported financially by National Natural Science Foundation of P. R. China (30500358), the National ' 973 ' programme of P. R. China (2006CB102102), the National High Technology Development Project and Natural Science Foundation of Hubei Province (2005ABA142). The authors gratefully acknowledge Dr Zhang JH for providing part of the microsatellite information. The authors also acknowledge the teachers and graduate students of the Key Laboratory of Swine Genetics and Breeding, Ministry of Agriculture, and the Swine Breeding Center of China for the collection of meat quality information.

\section{References}

Cirera S, Jorgensen CB, Sawera M, Raudsepp T, Chowdhary BP and Fredholm M 2003. Comparative mapping in the pig: localization of 214 expressed sequence tags. Mammalian Genome 146, 405-426.

Clop A, Ovilo C, Perez-Enciso M, Cercos A, Tomas A, Fernandez A, Coll A, Folch JM, Barragan C, Diaz I, Oliver MA, Varona L, Silio L, Sanchez A and Noguera JL 2003. Detection of QTL affecting fatty acid composition in the pig. Mammalian Genome 14, 650-656.

De Koning DJ, Janss LL, Rattink AP, Van Oers PA, De Vries BJ, Groenen MA, Van der Poel JJ, De Groot PN, Brascamp EW and Van Arendonk JA 1999. Detection of quantitative trait loci for backfat thickness and intramuscular fat content in pigs. Genetics 1524, 1679-1690.

Fan CY, Pan J, Chu R, Lee D., Kluckman KD, Usuda N, Singh I, Yeldandi AV, Rao MS, Maeda N and Reddy JK 1996. Hepatocellular and hepatic peroxisomal alterations in mice with a disrupted peroxisomal fatty acyl-coenzyme A oxidase gene. Journal of Biology Chemistry 271, 24698-24710.

Fenger M, Poulsen P, Beck-Nielsen H and Vaag A 2000. Impact of the Xbalpolymorphism of the human muscle glycogen synthase gene on parameters of the insulin resistance syndrome in a Danish twin population. Diabetic Medicine $1710,735-740$. 
Fontanesi L, Davoli R, Nanni Costa L, Scotti E and Russo V 2003. Study of candidate genes for glycolytic potential of porcine skeletal muscle: identification and analysis of mutations, linkage and physical mapping and association with meat quality traits in pigs. Cytogenetic and Genome Research 102, 145-151.

Green P, Falls K and Crooks S 1990. Document for CRIMAP, version 2.4. Washington University School of Medicine, St Louis, MO, USA.

Haley CS, Knott SA and Elsen JM 1994. Mapping quantitative trait loci in cross between outbred lines using least square. Genetics 136, 1195-1207.

Kim SJ, Sohn I, Ahn JI, Lee KH, Lee YS and Lee YS 2004. Hepatic gene expression profiles in a long-term high-fat diet-induced obesity mouse model. Gene 340, 99-109.

Liu BH 1998. Statistical genomics: linkage, mapping, and QTL analysis. CRC Press, Boca Raton, FL, USA.

Malek M, Dekkers JCM, Lee HK, Bass TJ and Rothchild MF 2001. A molecular genome scan analysis to identify chromosomal regions influencing economic traits in the pig. II. Meat and muscle composition. Mammalian Genome 12, 637-645.

Motoyama K, Emoto M, Tahara H, Komatsu M, Shoji T, Inaba M and Nishizawa Y 2003. Association of muscle glycogen synthase polymorphism with insulin resistance in type 2 diabetic patients. Metabolism 527, 895-899.

Orho-Melander M, Almgren P, Kanninen T, Forsblom C and Groop LC 1999. A paired-sibling analysis of the $X b a l$ polymorphism in the muscle glycogen synthase gene. Diabetologia 429, 1138-1145.

Ovilo C, Fernandez A, Rodriguez MC, Nieto M and Silio L 2006. Association of MC4R gene variants with growth, fatness, carcass composition and meat and fat quality traits in heavy pigs. Meat Science 73, 42-47.

Rissanen J, Pihlajamaki J, Heikkinen S, Kekalainen P, Mykkanen L, Kuusisto J, Kolle A and Laakso M 1997. New variants in the glycogen synthase gene
(GIn71His, Met416Val) in patients with NIDDM from eastern Finland Diabetologia 4011, 1313-1319.

Shimomura H, Sanke T, Ueda K, Hanabusa T, Sakagashira S and Nanjo K 1997. A missense mutation of the muscle glycogen synthase gene (M416V) is associated with insulin resistance in the Japanese population. Diabetologia 408, 947-952.

Statistical Analysis Systems Institute 2000. User's guide, version 8.0. SAS Institute Inc., Cary, NC, USA.

Te Pas MF, Leenhouwers Jl, Knol EF, Booij M, Priem J and Van der Lende T 2003. Marker polymorphisms in the porcine genes for muscle glycogen synthase (GYS1) and muscle glycogen phosphorylase (PYGM). Animal Genetics $342,157-158$

Varona L, Gomez-Raya L, Rauw WM and Noguera JL 2005. A simulation study on the detection of causal mutations from $F_{2}$ experiments. Journal of Animal Breeding and Genetics 122, 30-36.

Webb AJ 1998. Objective and strategies in pig improvement and applied perspective. Journal of Animal Science 81(Suppl. 2), 36-46.

Xiong YZ and Deng CY 1999. Principle and method of swine testing. Chinese Agricultural Press, Beijing.

Zhang JH, Xiong YZ, Zuo B, Lei MG, Jiang SW, Li FE., Zheng R and Li JL 2007. Genetic analysis and linkage mapping in a resource pig population using microsatellite markers. Journal of Genetics and Genomics 341, 10-16.

Zuo B, Xiong YZ, Su YH, Deng CY, Zheng R and Jiang SW 2003. Mapping quantitative trait loci for meat quality on pig chromosome 3, 4 and 7. AsianAustralian Journal of Animal Science 16, 320-324.

Zuo B, Xiong YZ, Deng CY, Su YH, Wang J, Lei MG, Li FE, Jiang SW and Zheng R 2005. Polymorphism, linkage mapping and expression pattern of the porcine skeletal muscle glycogen synthase (GYS1) gene. Animal Genetics 36, 254-257. 